\title{
SIMULASI THERMAL TRANSIENT KACA LEMBARAN TERPAPAR TEMPERATUR RADIASI DENGAN ANALISA THERMAL STRESS
}

\author{
Eko Julianto, Waluyo Adi Siswanto \\ Magister Teknik Mesin Fakultas Teknik Universitas Muhammadiyah Surakarta \\ Jl. A. Pabelan,Kartasura kota Surakarta \\ Email: Eckojuliant87@Gmail.com
}

\begin{abstract}
ABSTRAK
Untuk melakukan pengujian temperatur radiasi. Peneliti menggunakan simulasi untuk mempelajari perilaku kerusakan atau keretakan kaca float lembaran menggunakan sofware Mecway 8 FEA. Dimana waktu dan suhu sekitar pada lembaran kaca float yang pertama mengalami perubahan temperatur adalah parameter yang paling utama untuk mengetahui bagian kaca yang retak. Analisa hasil simulasi dari paparan panas radiasi dan konveksi mensimulasikan thermal transient kepermukaan kaca lembaran menjadi rusak atau retak dan mengetahui perkiraan waktu sampai kaca lembaran retak dengan simulasi thermal stress. Memberikan temperatur radiasi ke permukaan lembaran kaca, diasumsikan dengan paparan temperatur dari kurang lebih 20 menit yaitu $32^{\circ}$ sampai $150^{\circ} \mathrm{C}$ dengan ketebalan kaca $4 \mathrm{~mm}$ menggunakan software Mecway 8 FEA. Pada proses ini hasil simulasi dan exsperiment juga akan dibahas pada batas besaran temperatur radiasi sehingga lembaran kaca retak atau thermal shock. Perbedaan temperatur dan waktu akan meningkat seiring bertambahnya temperatur radiasi pada lembaran kaca. Waktu kritis dan perbedaan termperatur sebagai nilai referensi untuk memprediksi Thermal stress dalam aplikasi software Mecway 8 Fenite element analisis.
\end{abstract}

Kata Kunci: Temperatur , Transient, Stress, Retak, Mecway 8

\begin{abstract}
To test radiation temperature. The researcher used a simulation to study the behavior of damage or cracking of sheet float glass using Mecway 8 FEA software. Where time and ambient temperature on sheet float glass that first experience temperature changes are the most important parameters to find out the part of the glass that is cracked. Analysis of simulation results from exposure to radiation and convection heat simulates thermal transient surface glass sheets to be damaged or cracked and to know the estimated time to crack sheet glass with thermal stress simulation. Giving radiation temperature to the surface of the glass sheet, assumed by exposure to temperatures of approximately 20 minutes, namely $32^{\circ}$ to $150^{\circ} \mathrm{C}$ with an thickness of $4 \mathrm{~mm}$ glass using Mecway $8 \mathrm{FEA}$ software. In this process the simulation results and experiments will also be discussed at the radiation temperature limit so that the glass sheet is cracked or thermal shock. The difference in temperature and time will increase with increasing radiation temperature on the glass sheet. Critical time and temperature differences as reference values for predicting Thermal stress in application software Mecway 8 Fenite elements analysis.
\end{abstract}

Keywords: Temperature, Transient, Stress, Crack, Mecway 8 


\section{PENDAHULUAN}

Kaca jendela bening tidak lebih baik dari kaca abu - abu yang sudah diteliti sebagai energi kaca yang paling efisien karna dapat mengurangi beban pendinginan saat terkena panas maksimum didalam gedung atau bangunan dibandingkan bahan kaca yang lainnya [1]

Menggunakan model kaca komputasi terbaru untuk menilai kemampuannya dalam mereplikasi laju tingkat kerusakan kaca. [2]. Menurut Kenny memperkirakan batas atas dan batas bawah suhu leleh setiap kaca, kemudian masing - masing kaca telah di simulasikan kerusakan akibat radiasi panas struktur bisa dalam bentuk lonjakan thermal terkonsentrasi atau lebih berdifusi dengan koposisi kaca dan rasio atom yang lebih tinggi. [3] Jika kaca tibatiba terkena panas yang ekstrim, kejutan akan menyebabkan kaca pecah.[4] Kaca bangunan berperforma tinggi yang dapat secara efektif mengurangi konsumsi energy karna sifat thermal dan optik, peningkatan ketebalan dapat secara efekktif menurunkan efek radiasi panas cahaya matahari dan koefisien perpindahan panas.[5]

Perlakuan panas konvensional terhadap pembakaran kaca memiliki masalah dominan dengan konsumsi waktu yang tinggi konsumsi energi dan biaya produksi yang rendah ini membutuhkan pengembangan proses alternatif. [6]. Perolehan radiasi panas matahari dari jenis kaca yang umum digunakan telah dihitung dan di analisis yang di ukur dengan pengukuran di uji dengan distribusi panas radiasi matahari dalam ruangan dengan menggunakan jenis kaca yang berbeda - beda.[7].

Penggunaan kaca dibatasi oleh kerapuhan dan kekuatannya yang tinggi, oleh karna itu penting untuk mengetahui studi tentang fraktur kaca dibawah beban statis dan dinamis [8].

Maka dari itu penelitian selanjutnya adalah meneliti temperatur radiasi, waktu retak dan membandingkan penelitian sebelumnya dengan hasil simulasi yang akan dilakukan dalam penelitian ini menggunakan komputisasi software Mecway 8 fenite element analisis.

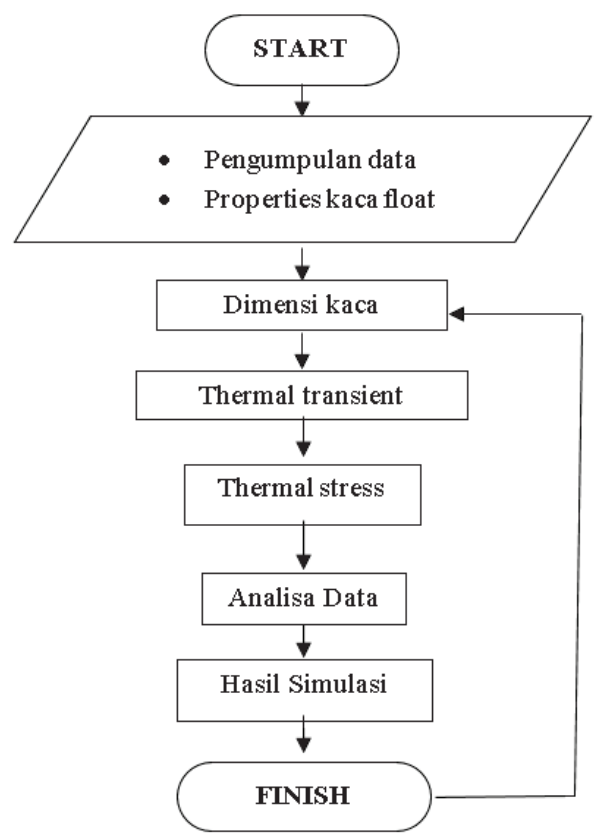

Gambar .1. Diagram Alir Penelitian

\section{METODE PENELITIAN}

Proses analisis dijalankan menggunakan software Mecway 8 yang dapat mengahasilkan output sesuai jenis analisa yang dilakukan pada simulasi. Setelah output diketahui, kemudian 
dapat dibandingkan bagaiamana hasil dari masing - masing ketebalan kaca dan melakukan pengujian variasi temperatur proses pengujian kaca untuk mengetahui batas maksimal suhu paparan radiasi sampai kaca mengalami retak / crack, dengan analisis thermal stress, waktu ideal dan panas yang telah ditentukan.

\section{Teori Analisis Data}

Analisis thermal transient suhu dan kuantitas panas lainnya yang bervariasi dari waktu ke waktu. Suhu yang di analisis dihitung sebagai masukan untuk evaluasi thermal stress, Perbedaan utama adalah bahwa sebagian besar beban yang diterapkan dalam thermal transient adalah fungsi waktu.

Metode fenite element analisis ( FEA ) pada sofware Mecway 8 digunakan untuk menganalisa thermal transient dan thermal stress pada lembaran kaca float. Metode elemen hingga FEM adalah alat potensial untuk mengukur tegangan termal dalam bahan padat, dan oleh karena itu,itu diambil untuk menganalisis thermal stress kaca dalam api. Untuk bidang kaca, ketebalannya jauh lebih kecil ukurannya dari arah panjang dan lebar, dan kemudian dua dimensi FEM diambil di sini. Pertama, suhu gelas dihitung dan kemudian tegangan termal dihitung berdasarkan hasil suhu. [9] the high temperature encountered could induce important stresses in glass panes, resulting into cracks and possible fallout of the glazing. The aim of the present work is to investigate thermal stress distributions in a glazing system for fire scenarios. A two dimensional glass thermal stress model to calculate the transient temperature and thermal stress distributions in a typical window glass under fire conditions was developed based on the Kong's work. The basic thermal conduction equation and thermal stress equation for glass were discretized by using the Galerkin method. A computer program based on the model was also developed. For validation purposes, simulations have been carried out using literature experimental data on glazing behavior in an enclosure fire. The glass surface temperature (exposed side.

\section{Metode Simulasi Mecway 8 FEA}

Dalam metode ini, kami menganalisa hasil fenite element analisis ( FEA ) pada sofware Mecway dengan membandingkan hasil eksperiment yang didapat peneliti sebelumnya dari publikasi Zhang dkk, dari hasil simulasi akan digabungkan dengan hasil eksperiment dalam bentuk sebagai berikut:

Kabin yang dirakit adalah $2000 \mathrm{~mm} \times 1000 \mathrm{~mm} \times 1000 \mathrm{~mm}$, terdiri dari 5 bagian yang dapat dilepas dengan panjang 500mm, 500mm, 500mm, 200mm, 200mm dan $100 \mathrm{~mm}$.[10].

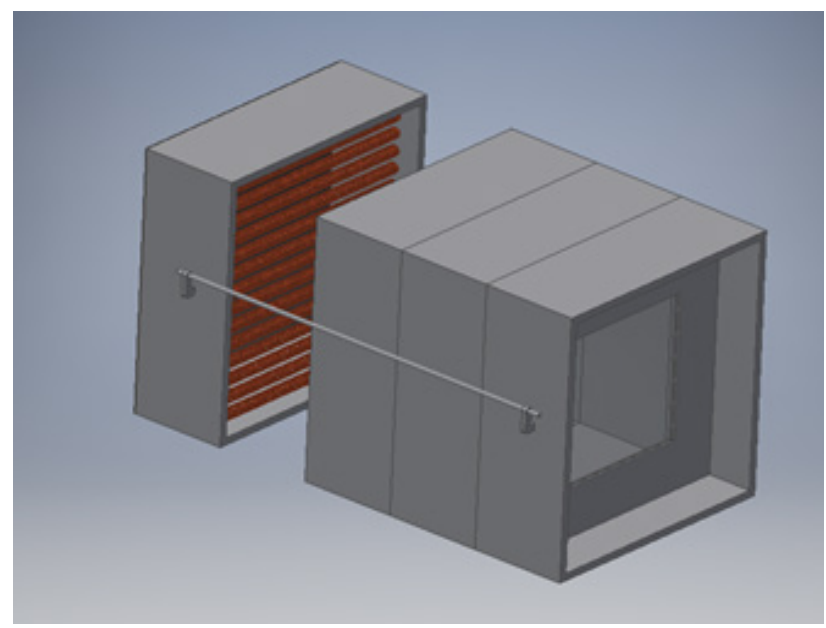

Gambar.2. Kabin Kabinet Pemanas Kaca 
Kaca float digunakan dengan margin halus dan ukuran kaca adalah $600 \mathrm{~mm} \times 600 \mathrm{~mm}$. Ketebalan kaca yang digunakan dalam percobaan adalah $4 \mathrm{~mm}$ yang diproduksi. Desain kaca merujuk pada SNI 15-0047-2005/standart nasional indonesia dan BSN / badan standarisasi nasional. [11],[12].
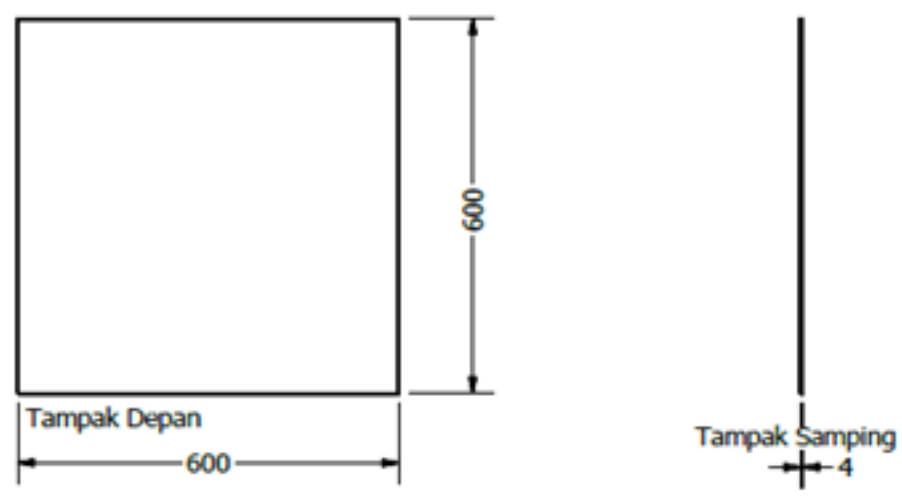

Gambar.3. Dimensi Kaca 4 mm

Ketika kaca terkena api, perpindahan panas dari api ke kaca terutama dialirkan oleh panas radiasi dari api dan konveksi panas dari lapisan gas panas. Sedangkan perpindahan panas di dalam gelas adalah dibatasi oleh tiga kondisi batas dasar. Kondisi batas pertama adalah bahwa suhu batas diketahui, dan yang kedua adalah bahwa fluks panas batas diketahui, dan yang ketiga adalah bahwa suhu tetap substansi dan koefisien perpindahan panas diketahui.

Untuk menjalankan proses analisa simulasi diperlukan nilai dari sifat material yaitu sifat karakteristik atau sifat fisik dari kaca float lembaran untuk mengetahui berat jenis, modulus young dan lain sebagainya agar mendapatkan hasil simulasi yang diinginkan dan sangat bermanfaat bagi peneliti untuk membandingkan dengan hasil simulasi dari jurnal ilmiah yang terdahulu.

Tabel .1.Sifat Fisik dan Mekanik Kaca.[11]

\begin{tabular}{cccc}
\hline NO & Jenis & Nilai & Satuan \\
\hline 1 & Indek Bias & 1.52 & $.-\cdot-\cdot$ \\
2 & Indek pantulan & 4 & $\%$ \\
3 & Panas Jenis & $0-50$ & ${ }^{\circ} \mathrm{C}$ \\
4 & Titik Lunak & $720-730$ & ${ }^{\circ} \mathrm{C}$ \\
5 & Konduksi Panas & 0.68 & $\mathrm{kcal} / \mathrm{mhr}^{\circ} \mathrm{C}$ \\
6 & Koefisien muai panjang & $8,5-9 \times 10-6$ & ${ }^{\circ} \mathrm{C}$ \\
7 & Berat Jenis & 2500 & $\mathrm{~kg} / \mathrm{cm}^{2}$ \\
8 & Modulus young & 720,000 & $\mathrm{~kg} / \mathrm{cm}^{2}$ \\
9 & Angka Poison & 0,25 & $.--\cdot-\cdot-\cdot$ \\
10 & Tegangan Pecah & 500 & $\mathrm{~kg} / \mathrm{cm}^{2}$ \\
\hline
\end{tabular}




\section{Tahap Proses Simulasi}

Dalam simulasi panas radiasi pada Mecway 8 FEA / fenite elemen analisis, nilai dari sifat material kaca float sangatlah penting karna kaca float bnyak digunakan di dunia dan khususnya indonesia sebagai kaca bangunan pada gedung atau rumah pribadi. Dan Tabel 1 diatas menunjukkan parameter yang diimport ke file input sebelum perhitungan. Dalam perhitungan elemen hingga step-by-step, generasi mesh otomatis diperlukan setelah crack.
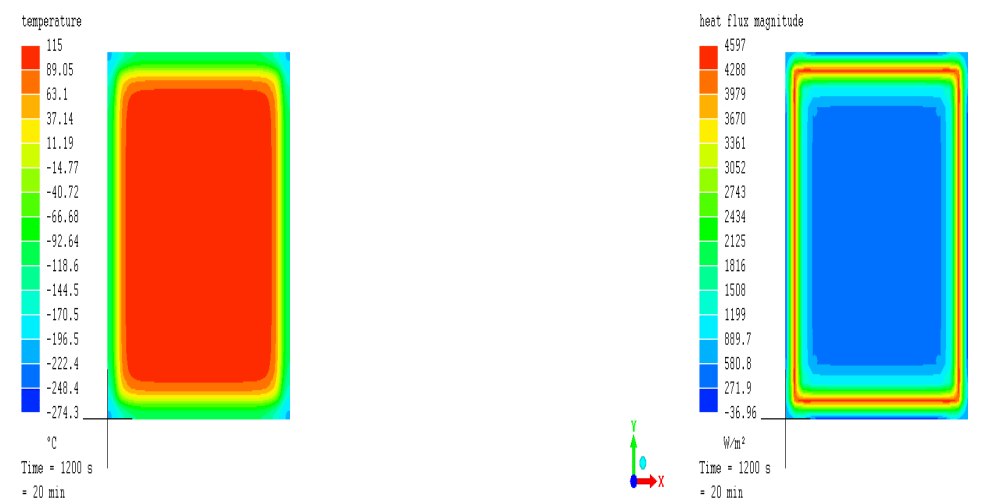

Gambar .4.Simulasi Thermal Transient Kaca Terhadap Waktu

Dari hasil simulasi pada Mecway diatas terlihat pada Gambar 4 bahwa suhu temperatur tertinggi adalah $115{ }^{\circ} \mathrm{C}$ dan Temperatur terendah adalah $37,14{ }^{\circ} \mathrm{C}$ dari suhu sekitar / ambient themperature yang ada di indonesia perikiraan sekitar $32^{\circ} \mathrm{C}$, disimpulkan bahwa dalam simulasi thermal transient ini dipengaruhi dari berapa waktu pemanasan radiasi pada kaca. Dari sumber pemanas awal dan suhu sekitar $32{ }^{\circ} \mathrm{C}$, ke suhu paling tinggi titik awal pemanas $150^{\circ} \mathrm{C}$ sampai pada lapisan tengah kaca $115,0{ }^{\circ} \mathrm{C}$. Suhu maksimal sampai ditepi kaca antara rangka $29,79{ }^{\circ} \mathrm{C}$ dan suhu minimum adalah $11,19{ }^{\circ} \mathrm{C}$ dan flux panas / heat flux tertinggi atau maksimal adalah $4597 \mathrm{w} / \mathrm{m}^{2}$ dan minimum $2627 \mathrm{w} / \mathrm{m}^{2}$ dari waktu pemanasan 0 menit sampai 20 menit.

Untuk mengetahui keretakan pertama dalam kaca lembaran maka peneliti akan mensimulasikan kaca dengan cara mencari thermal stress dari batas luluh / yield kaca seperti yang tertera gambar dibawah ini.
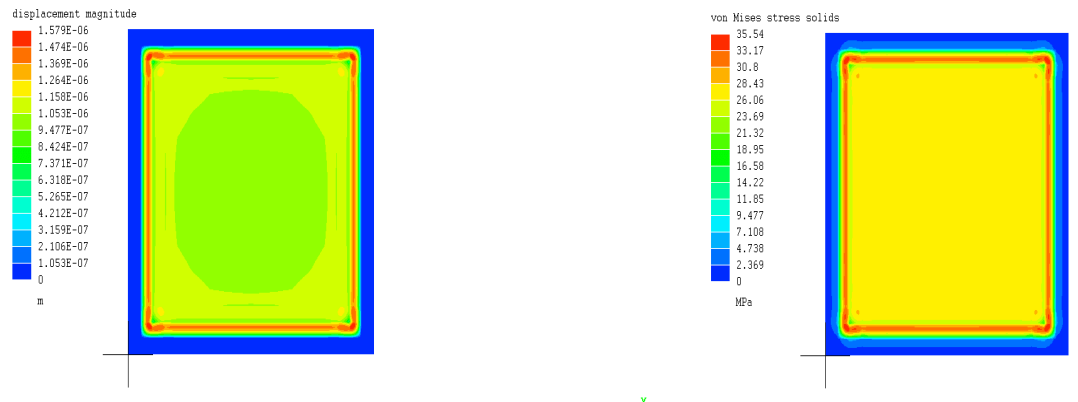

Gambar .5. Simulasi Thermal Stress Kaca Dari Batas Tegangan Luluh

Model thermal stress yang diaplikasikan dengan dimensi 3D hexagonal 20 ( hex20) untuk mempermudah dalam penentuan node dan element pada simulasi, Pada bagian ini node dan element digunakan untuk menyelidiki lebih banyak merinci efek berbagai kondisi batas pada thermal stress kaca jendela yang diaplikasikan untuk panas radiasi . 
Hasilnya juga dapat berfungsi sebagai data verifikasi untuk yang lain peneliti melakukan penelitian serupa di masa depan seperti yang ada hampir tidak ada data seperti itu dalam literatur untuk aplikasi api. Data eksperimental dalam literatur untuk kaca dalam kondisi kebakaran sebagian besar waktu untuk terjadinya retak pertama dan kaca permukaan suhu.

\section{HASIL DAN PEMBAHASAN}

Pada hasil simulasi menggunakan FEA/fenite elemen analsis digunakan untuk penyelidikan lebih lanjut yaitu dengan menganalisa hasil output data ang ada pada fenite elemen analisis di dalam sofware Mecway 8, untuk di import ke dalam tabel dan dibuat menjadi alur grafik dari berbagai kondisi panas dan stress. Analisis ini penting untuk selanjutnya memverifikasi node dan element dalam dimensi kaca float, tetapi juga untuk pemahaman yang lebih baik tentang bagaimana berbagai parameter ini mempengaruhi kerusakan pada kondisi kebakaran.

Pada nilai node aliran panas menyebar keseluruh kaca dari tengah sampai ke tepi bingkai kaca bisa dilihat dari gradient warna biru, hijau, kuning, oranye dan merah. Merah adalah stress yang paling besar dari antara gradient warna lain terlihat pada Gambar 5 kaca mengalami pemuaian, bisa dilihat pada warna oranye yaitu 33,17 Mpa sampai ke warna merah 35,54 Mpa. Untuk nilai element dimulai pada permukaan tengah kaca yaitu warna oranye adalah 33,54 Mpa dan ke warna merah 35,93 Mpa.

Dapat diasumsikan bahwa perhitungan Fenite element analisis pada nilai node dan nilai element kurang lebih sama dirata - ratakan yaitu 35,54 Mpa, data yang lebih specifik dapat kita lihat pada hasil simulasi yang telah di input ke grafik seperti dibawah ini.

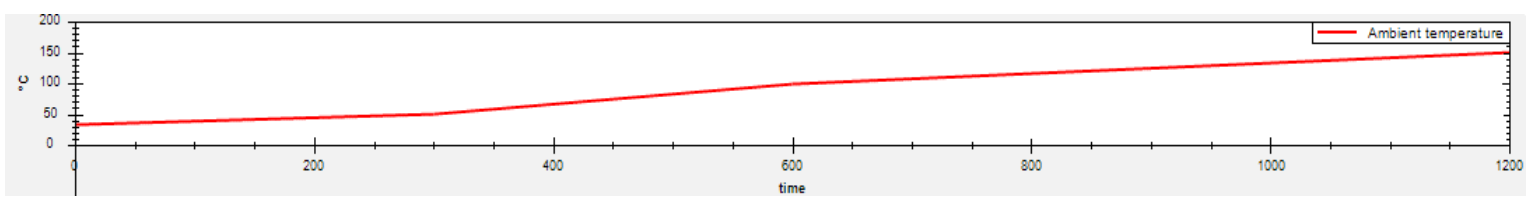

(a)

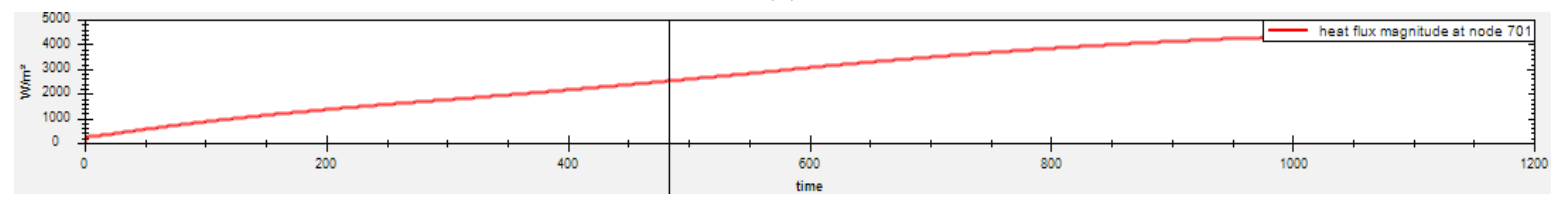

(b)

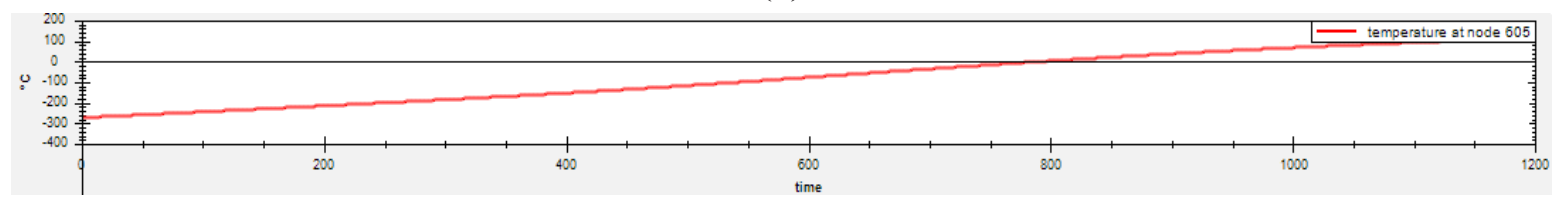

(c)

Gambar.6. Grafik Temperatur dan flux panas Terhadap Batas Waktu

Karna thermal transient adalah Analisis thermal transient suhu dan kuantitas panas lainnya yang bervariasi dari waktu ke waktu maka gradient panas radiasi pada lembaran kaca pada Gambar 6 terdapat variabel suhu sebelum panas puncak atau kaca mengalami kerusakan dari batas yield stress pada kaca yaitu $37,14{ }^{\circ} \mathrm{C}$ ke suhu yang sesuai gradient warna kuning yaitu $72,14{ }^{\circ} \mathrm{C}$ dalam waktu pemanasan kurang lebih 1005 detik sama dengan 16,75 menit. Di menit 1114 detik sama dengan 18,57 menit kaca mulai mengalami tegangan / thermal stress dari sisi tengah permukaan kaca dengan panas maksimum $115,0{ }^{\circ} \mathrm{C}$ dan sisi di dalam rangka / bingkai kaca suhu minimum $29,79{ }^{\circ} \mathrm{C}$. terlihat pada grafik bahwa mulai perubahan panas dimulai dari 
5,45 menit yaitu $37,14{ }^{\circ} \mathrm{C}$ dan panas akhir adalah $115,0{ }^{\circ} \mathrm{C}$. Untuk detailnya hasil simulasi dan penelitian ini lihat di tabel 2 berikut ini.

Tabel 2. Simulasi Panas Pada Waktu dan Parameter Waktu Pecah

\begin{tabular}{cccccc}
\hline No & $\begin{array}{c}\text { Time Step } \\
(\mathrm{min})\end{array}$ & $\begin{array}{c}\text { Temperatur } \\
(\mathrm{c})\end{array}$ & $\begin{array}{c}\text { Heat Flux } \\
\mathrm{w} / \mathrm{m}^{2}\end{array}$ & $\begin{array}{c}\text { Static } \\
(\mathrm{Mpa})\end{array}$ & $\begin{array}{c}\text { Crack Time } \\
(\mathrm{s})\end{array}$ \\
\hline 1 & 0 & 12,49 & 3361 & 2.369 & 1017 \\
2 & 5 & 37,14 & 3670 & 18.95 & 1048 \\
3 & 10 & 63,01 & 3979 & 28.43 & 1104 \\
4 & 15 & 89,05 & 4288 & 33.17 & 1151 \\
5 & 20 & 115,0 & 4597 & 35.54 & 1200 \\
\hline
\end{tabular}

Analisa selanjutnya adalah mengetahui nilai besarnya perpindahan thermal stress pada kaca sehingga bisa diasumsikan kaca retak atau pecah yaitu nilai maksimum adalah 0,001579 $\mathrm{mm}$ dan minimum sekitaran $0,001053 \mathrm{~mm}$ dari reaction force sebesar $3,257 \mathrm{~N}$. dan untuk lebih mudahnya bisa dilihat pada grafik alir dan tabel hasil analisa menggunakan software Mecway 8 diatas.

Dalam proses pemberian panas radiasi jumlah node dan elemen pada aplikasi sofware Mecway sangat berpengaruh besar pada proses perlakuan panas yang berlangsung selama 20 menit, selain itu kaca yang digunakan adalah kaca yang sering ditemukan pada bangunan yang ada di indonesia, karna harganya yang murah dan mudah di dapat. Maka dari itu sangat penting penelitian ini ntuk mengetahui kekuatan kaca saat terkana panas apabila terkena panas api. Dan selain itu adalah salah satu yang paling awal retak adalah bagian tengah apabila suhu tegak lurus kedepan permukaan kaca float, seperti yang terlihat pada Gambar.4, dan Karena waktu retaknya adalah nilai yang sesuai pada thermal stress dan batas yield stress yang ditentukan . terlihat dari Gambar. 5, bisa di asumsikan bahwa hampir semua retakan awal terjadi di tepi panel kaca atau batas dari rangka kaca itu, di mana tekanan termal maksimal di seluruh kaca dan terjadi stress yang besar anatara tepi kaca dan rangka. Terlihat pada gradient warna yang merah dan oranye. Pada saat sebelum retakan pertama, tegangan pertama keluar dengan hasil kekuatan kaca dan distribusi tegangan / stress.

Hasil perhitungan dan analisis dapat membantu kita untuk menentukan kasus mana yang relatif lebih aman dan memberikan masukan secara teknik untuk kaca. Stres dan transient juga dapat disimulasikan hanya dengan mengganti sifat thermal jenis kaca atau kondisi yang terpapar radiasi berubah. Ini dapat menghasilkan banyak desain jendela yang digunakan untuk memverifikasi apakah kaca float cukup untuk aplikasi software tertentu khususnya dibidang simulasi panas pada kaca.

\section{KESIMPULAN}

Dalam analisis simulasi ini terdapat kasus yang dapat disimpulkan bahwa kaca float lembaran adalah kaca yang kurang baik dalam penghantar panas karna sifat kristalnya yang menyebabkan panas tidak dapat merata keseluruh permukaan, Pada bangunan di indonesia karna kaca float lembaran mempunyai sifat material yang sangat rapuh, selain itu dalam menggunakan simulasi fenite elemen analisis pada Mecway sangatlah mendekati karna semua angka dari hasil perhitungan dan simulasi fenite elemen sangat membantu kami untuk pengolahan data, seperti pembuatan alur waktu dan tegangan / stress panas pada kaca. Dan kami juga menyimpulkan bahwa kaca setelah diberi paparan temperatur radiasi dengan suhu maksimal $115^{\circ} \mathrm{C}$ kaca sudah mulai mengalami perubahan bentuk / fraktur dimana pusat panas untuk pemapar api sekitar $150^{\circ} \mathrm{C}$ dengan perbedaan waktu dari 16,75 detik sampai 20 menit. Sedangkan untuk 
thermal stress kaca float mendapatkan tegangan / stress maksimal yaitu 35,54 Mpa. Dan dapat disimpulkan bahwa kaca yang mengalami pecah atau retak yaitu bagian yang berwarna merah gambar.5 atau tepi rangka kaca. Untuk lebih jelasnya dibandingkan dengan gambar pada jurnal exsperimen sebelumnya yang menunjukkan tepi kaca juga mengalami retak dengan panas yang hampir sama dan menyerupai.

Disimpulkan bahwa perangkat fenite elemen analisis pada Mecway 8 sangat membantu dalam penelitian ini dan yang akan datang untuk meminimalisir penggunaan pada kaca yang dipakai dalam bangunan dan juga untuk lebih memperhatikan perangkat yang akan digunakan pada simulasi software lain karna pada saat simulasi berlangsung apabila jumlah node dan element lebih banyak maka hasilnya akan lebih halus dan gradient warnanya akan lebih sempurna.

\section{DAFTAR PUSTAKA}

[1] G. K. Kumar, S. Saboor, and T. P. A. Babu, "Experimental and Theoretical Studies of Window Glazing Materials of Green Energy Building in Indian Climatic Zones," Energy Procedia, vol. 109, no. November 2016, pp. 306-313, 2017.

[2] C. E. Anderson and T. J. Holmquist, "Computational Modeling of Failure for Hypervelocity Impacts into Glass Targets," Procedia Eng., vol. 58, pp. 194-203, 2013.

[3] K. Jolley and R. Smith, "Nuclear Instruments and Methods in Physics Research B Iron phosphate glasses : Structure determination and radiation tolerance," Nucl. Inst. Methods Phys. Res. B, vol. 374, pp. 8-13, 2016.

[4] Q. Wang, H. Chen, Y. Wang, and J. Sun, "Thermal shock effect on the glass thermal stress response and crack propagation,” Procedia Eng., vol. 62, pp. 717-724, 2013.

[5] Y. Lv, R. Huang, H. Wu, S. Wang, and X. Zhou, "ScienceDirect ScienceDirect Study on Thermal and Optical Properties and Influence Factors of Aerogel Glazing Units," Procedia Eng., vol. 205, pp. 3228-3234, 2017.

[6] P. Stief, J. Dantan, A. Etienne, and A. Siadat, “ScienceDirect ScienceDirect New process of tempering color printed glass by using laser irradiation A new methodology to analyze the functional and physical architecture of for an assembly oriented product family identification," Procedia CIRP, vol. 74, pp. 390-393, 2018.

[7] C. Zheng, P. Wu, V. Costanzo, Y. Wang, and X. Yang, "ScienceDirect ScienceDirect Establishment and Verification of Solar Radiation Calculation Model of Glass Daylighting Roof in Hot Summer and Warm Winter Zone in China," Procedia Eng., vol. 205, pp. 2903-2909, 2017.

[8] A. Nyounguè, S. Bouzid, E. Dossou, and Z. Azari, "Journal of Asian Ceramic Societies Fracture characterisation of float glass under static and dynamic loading," Integr. Med. Res., vol. 4, no. 4, pp. 371-380, 2016.

[9] Q. S. Wang, Y. Zhang, J. H. Sun, J. Wen, and S. Dembele, "Temperature and thermal stress simulation of window glass exposed to fire," Procedia Eng., vol. 11, pp. 452-460, 2011.

[10] Y. Zhang, Q. S. Wang, X. Bin Zhu, X. J. Huang, and J. H. Sun, "Experimental study on crack of float glass with different thicknesses exposed to radiant heating," Procedia Eng., vol. 11, pp. 710-718, 2011.

[11] P. One, P. Two, and P. Three, "PT Asahimas Flat Glass Tbk."1993.

[12] S. N. Indonesia and B. S. Nasional, "Kaca lembaran,” 2005. 